\title{
Ergonomic analysis at a workplace of a bicycle company using the Sue Rodgers tool
}

\author{
Sirlen Monteiro da Silva ${ }^{1}$, Worlen Ferreira Gimack ${ }^{2}$, Jandecy Cabral Leite Junior ${ }^{3}$
}

\author{
${ }^{1,2}$ Laureate International Universities - UNINORTE - Av. Djalma Batista, 2100 - N. Sr ${ }^{\mathrm{a}}$. das Graças, Plaza Shopping - Manaus - AM. \\ ${ }^{3}$ Instituto de Tecnologia e Educação Galileo da Amazônia (ITEGAM) - Av. Joaquim Nabuco, 1950, Centro - Manaus - AM
}

Email: sirlenmonteiro@ hotmail.com,worlen_gimack@hotmail.com,juniorcabra1929@hotmail.com

Received: June $20^{\text {th }}, 2017$

Accepted: September $25^{\text {th }}, 2017$

Published: September 30'th 2017

Copyright $@ 2016$ by authors and Institute of Technology Galileo of Amazon (ITEGAM). This work is licensed under the Creative Commons Attribution International License (CC BY 4.0).

http://creativecommons.org/licenses/by/4.0/ (c) (i) (2) Open Acces:

\begin{abstract}
Nowadays companies are investing more and more in the improvement of work methods and the ergonomic analysis becomes important in the area of work safety because it evaluates the degree of risk involved in the activities of the workers within the organizations. This article aims to perform an ergonomic analysis in a work station of a bicycle industry of the Industrial Polo of Manaus and measure the ergonomic risks that the employee is exposed. The methodology of this research is qualitative and quantitative. In relation to the objective is defined as exploratory and descriptive. In relation to means, it is described as a case study. Through photos and videos of the process it was possible to identify the main biomechanical movements performed by the collaborator. The tool used for ergonomic analysis is Sue Rodgers, who evaluates the degree of risk in the body regions of the employee. Therefore, it is concluded that the risks involved in activities are classified as low grade, with the exception of the legs that have a moderate degree of risk.
\end{abstract}

Keywords: Ergonomic analysis, degree of risk, Suzanne Rodgers Method.

\section{Análise ergonômica em um posto de trabalho de uma empresa de bicicletas utilizando a ferramenta Sue Rodgers}

\begin{abstract}
RESUMO
Atualmente as empresas estão investindo cada vez mais na melhoria de métodos de trabalho e a análise ergonômica se torna importante na área de segurança do trabalho, pois avalia o grau de risco envolvido nas atividades dos trabalhadores dentro das organizações. Este artigo tem como objetivo realizar uma análise ergonômica em uma estação de trabalho de uma indústria de bicicletas do Polo Industrial de Manaus e mensurar os riscos ergonômicos que o colaborador está exposto. A metodologia desta pesquisa é de caráter qualitativo e quantitativo. Em relação ao objetivo é definida como exploratória e descritiva. Em relação aos meios, é descrita como um estudo de caso. Através de fotos e vídeos do processo foi possível identificar os principais movimentos biomecânicos realizados pelo colaborador. A ferramenta utilizada para análise ergonômica é a Sue Rodgers, que avalia o grau de risco nas regiões corporais do colaborador. Logo, conclui-se que os riscos envolvidos nas atividades são classificados como grau baixo, com exceção das pernas que tem um grau de risco moderado.
\end{abstract}

Palavras Chaves: Análise ergonômica, grau de risco, Método Suzanne Rodgers.

\section{INTRODUÇÃO}

Nas últimas décadas, tem havido um aumento substancial da incidência de doenças osteomusculares (DORTs), que estão intimamente ligadas aos riscos dos novos processos de industrialização, cujos efeitos são muitas vezes incertos. Todos os processos produtivos de uma organização apresentam risco, e nesse contexto os trabalhadores permanecem por longos períodos 
em posições estáticas nos postos de trabalho, desempenhando tarefas mecânicas e repetitivas que podem ocasionar desconfortos físicos e por fim fadiga física e mental [1].

A cultura do trabalho de uma empresa deve ser focalizada na importância do homem, cuidando de sua saúde, qualidade de vida, e capacitação. Trabalhadores valorizados e satisfeitos produzem melhor e colaboram prazerosamente com o crescimento da empresa [2]. A organização do trabalho provoca situações de trabalho que exercem pressões e são geradores de estresse, isto é, que provocam e interferem no equilíbrio psíquico e mental do trabalhador [3].

Por definição, Ergonomia é conhecida, como um conjunto de conhecimentos científicos relativos ao homem e necessários para a concepção de ferramentas, máquinas e dispositivos que possam ser utilizados com o máximo de conforto, segurança e eficácia. A prática ergonômica é uma arte que utiliza técnicas e baseia-se em conhecimentos científicos [4].

Com a evolução do trabalho, a mentalidade empresarial passa a compreender que o trabalho deverá ser não somente um meio de sobrevivência, mas também uma motivação, permitindo tanto a satisfação física como a mental. Esta mudança ajudou a enxergar o homem como peça fundamental do sistema produção, alterando conceitos e surgindo o cuidado de adequar o trabalho, o equipamento e o meio ao homem.

Para uma perfeita análise do posto de trabalho, é necessário que haja uma observação ampla e cuidadosa visando respostas para questões como: do modo em que trabalho é conduzido por seu ator (o trabalhador), a organização do layout e mobiliário disponível, a questão da repetitividade dos movimentos, como se dá a relação entre os colaboradores e destes para com a chefia, se há níveis satisfatórios de conforto sonoro, conforto térmico, se o iluminamento é eficaz para a execução da atividade, etc.

Este trabalho tem como objetivo realizar uma análise ergonômica em um posto de trabalho de uma empresa de bicicletas do Polo Industrial de Manaus utilizando a ferramenta Suzanne Rodgers para a avaliação de riscos ergonômicos.

\section{REVISÃO BIBLIOGRÁFICA}

\section{II.1 CONCEITO DE ERGONOMIA}

Palavra de origem grega, Ergon-Trabalho, Nomos-Regra, o que poderia ser traduzido com regras para o trabalho, que na prática e tido como regras para amenizar ou evitar futuras lesões causadas por esforços repetitivos executados durante uma jornada de trabalho em determinado setor.

A [5] seguindo a classificação de domínios sugeridos pela [6] define a ergonomia física como aquela que: Está relacionada com as características da anatomia humana, antropometria, fisiologia e biomecânica em sua relação com a atividade física. Os tópicos relevantes incluem o estudo da postura no trabalho, manuseio de materiais, movimentos repetitivos, distúrbios musculoesqueléticos relacionados ao trabalho, projeto de posto de trabalho, segurança e saúde. Essas características anatômicas, antropométricas, fisiológicas e biomecânicas dos trabalhadores são confrontadas com as exigências físicas do posto de trabalho que podem ter as seguintes propriedades: de manuseio de materiais, de movimentos repetitivos, exposição a posturas desconfortáveis, de realização de força, de compressão mecânica, de trabalho estático e dinâmico [7].

"Ergonomia é o estudo do relacionamento entre o homem e o seu trabalho, equipamento, ambiente, particularmente, da aplicação dos conhecimentos de anatomia e fisiologia na solução dos problemas surgidos desse relacionamento" [6].
Para [8] estabelece que a ergonomia está preocupada com os aspectos humanos do trabalho em qualquer situação onde este é realizado. “... a ergonomia estuda diversos aspectos do comportamento humano no trabalho..." [9].

A ergonomia é uma área da ciência econômica que aborda tópicos relacionados com o contexto moderno de trabalho, sobretudo na economia industrial. Dois temas cruciais no âmbito da ergonomia são a segurança no trabalho e a prevenção dos acidentes laborais, e por isso a ergonomia sugere a criação de locais adequados e de apoios ao trabalho, cria métodos laborais e sistemas de retribuição de acordo com o rendimento (valorização, estudo do trabalho). A ergonomia também determina horários de trabalho, assim como a sua nacionalização, e contempla tudo através de uma perspectiva humanitária da empresa e das relações que se estabelecem nela. Ainda há outros tipos de ergonomia como a cognitiva e a organizacional, todas em amplo desenvolvimento em muitas corporações. Em Manaus mais exatamente no Polo Industrial nos últimos 10 anos as empresas vêm se adequando as normas de ergonomia como método de prevenção de futuros custos com alguma doença ocupacional dos funcionários.

\section{II.2 A ORIGEM DA ERGONOMIA}

Desde o começo das civilizações, o homem buscou adaptar ferramentas e utensílios de forma a facilitar o seu cotidiano. Nos primórdios, a sua confecção era artesanal e a produção em grande escala dificultava essa compatibilização de produtos ao usuário. Ao passo que a tecnologia avançava, essas adaptações tornaram-se cada vez mais necessárias, evidenciando que os fatores humanos são primordiais. Essas incompatibilidades entre o humano e o tecnológico evidenciou-se na Segunda Guerra Mundial, na qual os equipamentos militares exigiam de seus operadores decisões rápidas e execução de atividades novas em condições críticas, implicando em quantidade de novas informações, complexidade e riscos de decisões que envolviam possibilidade de erros fatais [10].

O termo ergonomia é utilizado pela primeira vez como ramo do saber específico, com objeto próprio e objetivos particulares, pelo psicólogo inglês K. F. Hywell Muffel, quando pesquisadores formaram uma sociedade para o estudo dos seres humanos em seu ambiente de trabalho - a Ergonomic Research Society - na qual o termo trabalho se aplicava a qualquer atividade humana que envolvesse grau de experiência ou esforço [11].

\section{II.3 A EVOLUÇÃO DA ERGONOMIA}

Os primeiros estudos voltados à ergonomia e a ciência do corpo humano começou a partir do século XV com Leonardo Da Vinci que através dos seus experimentos e projetos de pintura, arquitetura e matemática também observava a ciência do corpo humano, apesar de não ter se aprofundado muito no assunto. $\mathrm{O}$ objetivo da curiosidade científica de Leonardo da Vinci era o homem e o seu entorno, considerando as mais amplas relações, demonstrando claramente a preocupação central dos fatores humanos. Em seus estudos e projetos, as máquinas e suas funções se ajustavam ao homem, facilitando a execução de diversas ações. Embora Leonardo se intitulasse um homem sem estudos [12] sustenta a ideia de que ele tenha sido precisamente o inventor das ciências modernas, fundamentadas num método que se baseia na experiência e na matemática. De acordo com [13], o corpo humano é o ponto de partida para o projeto de produto. Dessa forma, os estudos minuciosos de Leonardo acerca da anatomia humana, principalmente seu estudo sobre "O Homem Vitruviano", são precursores essenciais do estudo da 
antropometria e da ergonomia. A ergonomia evoluiu dos esforços do homem em adaptar ferramentas, armas e utensílios às suas necessidades e características. Porém, é a partir da Revolução Industrial, que propiciou o surgimento da fábrica e a intensificação do trabalho, que a ergonomia vai encontrar sua maior aplicação [14].

\section{II.4 CONCEITO DE BIOMECÂNICA}

A Biomecânica estuda os movimentos dos homens e dos animais do ponto de vista das leis mecânicas [15]. A Biomecânica é a ciência da descrição e explicação mecânica das manifestações e causas dos movimentos, tomando-se por base as condições dos organismos [16]. A biomecânica está presente em todos os movimentos do ser humano: o comprimento da passada quando se caminha a angulação dos movimentos ao se alongar; ou seja, vai desde o simples gesto de levar o garfo com comida à boca, na hora do almoço, até a disputa de uma medalha olímpica no salto com vara. Com isso, a biomecânica visa, por meio dos conceitos da física clássica, a analisar e compreender os complexos movimentos do corpo humano. O princípio da Biomecânica nas articulações deve ser conservado, sempre que possível, em posição neutra, isto significa: Menor tensão dos ligamentos e músculos. Os músculos são capazes de liberar mais força (força máxima). Num conceito técnico a Biomecânica é aplicação de princípios mecânicos no estudo dos organismos vivos. Os estudos destes princípios mecânicos permitiram que se estudassem as melhores posições para uma atividade num posto de trabalho e avaliação conforme os movimentos das possíveis lesões que o posto pode causa a um funcionário.

Por outro lado, a biomecânica estuda as interações da postura no trabalho e no homem, do ponto de vista dos movimentos envolvidos e suas consequências. Nesta perspectiva, basicamente, a questão central apoia-se nas posturas corporais no trabalho e na aplicação das forças envolvidas [17].

\section{II.5 MÉTODO SUE RODGERS}

O método Sue Rodgers permite identificar quais as posturas mais danosas, para cada parte do corpo, na realização do trabalho, sua frequência e carga empregada. Avalia o nível de esforço (baixo, moderado e pesado) em pescoço, ombros, tronco, braços, mãos, punhos, dedos, pernas, pés e dedos. O formato do método, facilita as avaliações de funções e ajuda na identificação de tarefas que apresentam possibilidade de risco ergonômico.
Depois de aplicar o método, se conhecerá o risco relativo ao resultado apresentado por cada um dos movimentos a ação identificada na sua lista de realização. A técnica analítica pode facilitar a identificação das modalidades mais eficazes da redução de tensões. Aplica-se melhor como meio de determinação da natureza da tensão (intensidade, duração ou frequência), assim como a determinação do grau em que se é necessário alterar a função a fim de reduzir o risco de fadiga a um nível mínimo. O relatório de análise ergonômica de funções analisa os seis grupos musculares principais:Pescoço/ombros, tronco, braços/antebraços, punhos/mãos/dedos, pernas/joelhos, e tornozelos/pés/dedos dos pés. A finalidade do relatório é qualificar a intervenção de cada um dos grupos musculares em uma tarefa, a fim de determinar a gravidade de combinar certos aspectos da tarefa. O Nível de Esforço descreve o grau de esforço necessário que a tarefa exige a cada grupo muscular:

$$
\begin{array}{ll}
\checkmark & \text { Esforço Leve = 1 } \\
\checkmark & \text { Esforço Moderado = 2 } \\
\checkmark & \text { Esforço Pesado = 3 }
\end{array}
$$

Os tempos de esforço menores de 6 segundos se classificam $=1 ;$ os tempos que se mantém durante 6 e 20 segundos se classificam $=2$; os tempos que se mantêm igual ou mais de 20 segundos se classificam $=3$. Podem-se medir os tempos de esforço constante mediante o uso de cronômetro e contando "mil e um, mil e dois", etc. Basta uma contagem dentro de um segundo.

De acordo com [18], se a classificação do esforço é "pesado", então unicamente se deve medir a duração e a frequência do esforço pesado. Se depois de um esforço breve e pesado segue um esforço moderado empregado no mesmo grupo muscular, então se deve classificar por separado os tipos de esforço. Avaliam-se em conjunto pescoço e ombros e que muitas vezes funcionam em conjunto nas posturas laborais, os dedos se classificam junto com a mãos e os pulsos, e que devem se classificar por separado, as tarefas que implicam muito movimento do punho. Aplicam-se três níveis de esforço na descrição da tensão que exercem os grupos musculares: leve, moderado e pesado. Os dados que servem de fundamento para a técnica de análise ergonômica de funções representam três níveis sendo $30 \%, 60 \%$ e $85 \%$ da força muscular máxima nas posturas

\begin{tabular}{|c|c|c|c|c|c|c|c|c|c|c|}
\hline & & & & & $\begin{array}{r}\text { Esfo } \\
\text { MI }\end{array}$ & por & & \multicolumn{3}{|c|}{$\begin{array}{c}\text { GRUPO A } \\
\text { Verde }\end{array}$} \\
\hline \multirow{3}{*}{$\begin{array}{l}\text { Grupamento } \\
\text { Muscular } \\
\text { Avaliado }\end{array}$} & \multirow{2}{*}{\multicolumn{2}{|c|}{$\begin{array}{l}\text { 1- Leve } \\
\text { 2- Moderado } \\
\text { 3- Pesado }\end{array}$}} & \multirow{2}{*}{\multicolumn{2}{|c|}{$\begin{array}{l}1-0 \text { a } 6 \mathrm{seg} \\
2-7 \text { a } 20 \mathrm{seg} \\
3-+ \text { de } 20 \mathrm{seg} \\
4->15\end{array}$}} & \multirow{2}{*}{\multicolumn{2}{|c|}{$\begin{array}{l}1-0 \text { a } 1 \\
2-2 \text { a } 5 \\
3-+ \text { de } 5 \\
4->15\end{array}$}} & \multirow{2}{*}{$\begin{array}{c}\text { Resultado } \\
\text { Obtido }\end{array}$} & \multicolumn{3}{|c|}{ Outras Combinaçōes } \\
\hline & & & & & & & & \multicolumn{3}{|c|}{$\begin{array}{c}\text { GRUPO B } \\
\text { Amarelo }\end{array}$} \\
\hline & D & E & D & E & & $\mathrm{E}$ & & 123 & 231 & 222 \\
\hline \multicolumn{8}{|l|}{ Pescoço } & 132 & 213 & 232 \\
\hline \multicolumn{11}{|l|}{ Costas } \\
\hline \multirow{2}{*}{\multicolumn{11}{|c|}{ Ombros }} \\
\hline & & & & & & & & & & \\
\hline & & & & & & & & 223 & 321 & 233 \\
\hline $\begin{array}{ll}\text { Braços } & \boldsymbol{e} \\
\text { antebracos } & \end{array}$ & & & & & & & & 313 & 133 & 322 \\
\hline $\begin{array}{l}\text { Punhos, mâos e } \\
\text { dedos }\end{array}$ & & & & & & & & & $\begin{array}{l}\text { GRUPC } \\
\text { Púrpu }\end{array}$ & \\
\hline $\begin{array}{l}\text { Pernas, joelhos a } \\
\text { pés }\end{array}$ & & & & & & & & $\begin{array}{l}323 \\
333\end{array}$ & $\begin{array}{r}331 \\
X 4 X \text { ou }\end{array}$ & \\
\hline
\end{tabular}
empregadas no trabalho, respectivamente. A figura 1 mostra o Método Suzanne Rodgers.

Figura 1: Método Suzanne Rodgers.

Fonte: [18]. 
Da Silva, Gimack \& Leite Junior, ITEGAM-JETIA. Vol. 03, № 11, pp.13-21. Setembro, 2017.

A figura 2 mostra o grau de intensidade, esforço e frequência através do Método Suzanne Rodgers.

\begin{tabular}{|c|c|c|c|}
\hline \multicolumn{4}{|c|}{ NÍYEL DE ESFORÇO } \\
\hline & $\sin \alpha / \theta \cdot n \theta \gamma$ & 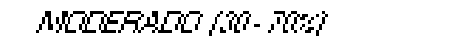 & 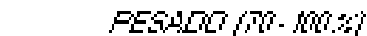 \\
\hline PESCOÇO & $\begin{array}{l}\text { A cabeça gira parcialmente } \\
\text { A cabeça esta ligeiramente ps } \\
\text { frente }\end{array}$ & $\begin{array}{l}\text { A cabeça gira totalmente para o lado } \\
\text { A cabeça esta totalmente para trás } \\
\text { A cabeça está para frente apron. } 20 \text {. }\end{array}$ & $\begin{array}{l}\text { Igual ao moderado porém } \\
\text { com aplicação de força } \\
\text { A cabeça está flexionada } \\
\text { acima de } 20 \text {. }\end{array}$ \\
\hline OMBROS & $\begin{array}{l}\text { Braços ligeiramente abduzidg } \\
\text { Braços extendidos com algur } \\
\text { suporte }\end{array}$ & $\begin{array}{l}\text { Braços abduzidos sem suporte } \\
\text { Braços flexionados (nível da cabeça) }\end{array}$ & $\begin{array}{l}\text { Aplica força ou sustentando } \\
\text { pesos com os braços } \\
\text { separados do corpo ou ao } \\
\text { nível da cabeça }\end{array}$ \\
\hline TRONCO & \begin{tabular}{|l|} 
Inclina ligeiramente para o lad \\
Flexiona ligeiramente o tronc:
\end{tabular} & $\begin{array}{l}\text { Fleviona para frente sem carga } \\
\text { Levanta carga de peso moderado } \\
\text { próximo ao corpo } \\
\text { Trabalho próximo ao nível da cabeça }\end{array}$ & $\begin{array}{l}\text { Levantando ou aplicando } \\
\text { força com rotaçẫo } \\
\text { Grande força com flexão } \\
\text { do tronco }\end{array}$ \\
\hline $\begin{array}{l}\text { BRAÇOS } \\
\text { ANTE- } \\
\text { BRAÇOS }\end{array}$ & $\begin{array}{l}\text { Braços ligeiramente afastadd } \\
\text { do corpo sem carga } \\
\text { Aplicação de pouca força ou } \\
\text { levantando pequena carga } \\
\text { próxima ao corpo }(\mathrm{F}<1 \mathrm{~kg}]\end{array}$ & $\begin{array}{l}\text { Rotação do braço, exigindo força } \\
\text { moderada }(1<\mathrm{F}<2,5 \mathrm{Kg})\end{array}$ & $\begin{array}{l}\text { Aplicaçẫo de grande força } \\
\text { com rotação } \\
\text { Levantamento de cargas } \\
\text { com os braços entendidos } \\
{[\mathrm{F}>2 \mathrm{Kg}]}\end{array}$ \\
\hline $\begin{array}{l}\text { MAOS } \\
\text { PUNHOS } \\
\text { DEDOS }\end{array}$ & $\begin{array}{l}\text { Aplicação de pequena força } \\
\text { objetos próximos ao corpo } \\
\text { Punho reto, com aplicação d. } \\
\text { força para agarre pequena } \\
{[\mathrm{F}<1 \mathrm{Kg}]} \\
\end{array}$ & $\begin{array}{l}\text { Area de agarre grande ou estreita } \\
\text { Moderado angulo do punho especial- } \\
\text { mente em flexấo } \\
\text { Uso de luvas com força moderada } \\
{[1<\mathrm{F}<2 \mathrm{Kg}]}\end{array}$ & $\begin{array}{l}\text { Pinçamento com dedos } \\
\text { Punho angulado com força } \\
\text { (F }>1 \mathrm{Kg} \text { ) } \\
\text { Superfície escorregadia } \\
\text { (F }>2 \mathrm{Kg} \text { ) }\end{array}$ \\
\hline \begin{tabular}{|l} 
PERNAS \\
JOELHOS \\
TORNOZELOS \\
PES E DEDOS
\end{tabular} & $\begin{array}{l}\text { Parado, caminhando sem } \\
\text { flexionar-se } \\
\text { Peso do corpo sobre os dois } \\
\text { pés }\end{array}$ & $\begin{array}{l}\text { Flexẫo para frente } \\
\text { Inclinar-se sobre a mesa de trabalho } \\
\text { Peso do corpo sobre um pé } \\
\text { Girar o corpo sem exercer força }\end{array}$ & $\begin{array}{l}\text { Exercendo grandes forças } \\
\text { para levantamento de } \\
\text { algum objeto } \\
\text { Agachar-se exercendo força }\end{array}$ \\
\hline
\end{tabular}

Figura 2: Interpretação do nível de esforço.

Fonte: [18].

\section{MATERIAIS E MÉTODOS}

\section{III.1 CLASSIFICAÇÃO DA PESQUISA}

Neste trabalho, o tipo de pesquisa utilizada é a pesquisa aplicada, pois há um interesse da empresa na aplicação de conhecimentos científicos para solução de problemas.

\section{III.2 CLASSIFICAÇÃO DA PESQUISA QUANTO À FORMA DE ABORDAGEM}

Esta pesquisa é definida como quali-quantitativa, pois foram utilizados dados numéricos com objetivo de obter opiniões ou informações sobre o desempenho do posto de trabalho através da utilização de tabelas para avaliar o seu comportamento e por utilizar entrevistas e coletas de dados para análise com intuito de gerar conceito ou significado sobre o campo em estudo visando uma melhor compreensão de um problema ou uma possível melhoria do sistema.

\section{III.3 TIPOLOGIA DA PESQUISA}

\section{III.3.1 CLASSIFICAÇÃO QUANTO AOS FINS}

A classificação desta pesquisa quanto aos fins foi definida de acordo com o conhecimento técnico do autor sobre o tema abordado, o objetivo a ser alcançado e a busca de uma resposta para a pergunta em questão. Em relação ao objetivo desta pesquisa, a mesma é classificada da seguinte forma: Exploratória e Descritiva.

\section{III.3.2 CLASSIFICAÇÃO DA PESQUISA QUANTO AOS MEIOS}

Esta pesquisa é definida como um estudo de caso, pois a partir da observação direta do processo de produção da empresa, é possível coletar dados referentes ao objeto de estudo e transformá-los em informações relevantes que irão auxiliar no processo decisório da empresa em relação às condições do posto de trabalho avaliado.

\section{III.4 PROCEDIMENTOS METODOLÓGICOS \\ III.4.1 POPULAÇÃO DA PESQUISA}

Nesta pesquisa a população é definida como número de funcionários da empresa, quantidade e postos de trabalho. Para a elaboração deste estudo se fez necessário separar uma parte (amostra) dessa população para realizar uma análise mais detalhada. Neste caso, foi escolhido um para a elaboração de uma análise ergonômica com o objetivo de avaliar os riscos ergonômicos do colaborador. 


\section{III.4.2 AMOSTRA DA POPULAÇÃO}

De acordo com a definição de [19], Amostra é o "Subconjunto do universo ou da população, por meio do qual se estabelecem ou se estimam as características desse universo ou população". A amostra desta pesquisa é uma parte de todo o sistema produtivo, ou seja, um posto de trabalho e um colaborador para a realização do estudo.

\section{III.5 INSTRUMENTOS DE COLETA DE DADOS}

\section{III.5.1 ENTREVISTA}

Entrevista é o "Encontro entre duas pessoas, a fim de que uma delas obtenha informações a respeito de um determinado assunto" [20]. A classificação desta entrevista é: não estruturada, ou seja, o funcionário responde as perguntas de forma direta sem um roteiro definido. $\mathrm{O}$ autor do trabalho foi $\mathrm{O}$ responsável pela entrevista.

\section{III.6 MATERIAIS E MÉTODOS UTILIZADOS NA PESQUISA}

\section{III.6.1 ORIGEM DOS DADOS}

A origem dos dados para a realização deste estudo foi levantada a partir da observação direta no processo produtivo da empresa, em específico no posto de trabalho avaliado.

\section{III.6.2 FORMATO DOS DADOS}

Os dados referentes ao processo de produção, objeto deste projeto de pesquisa, foram levantados pelo autor do trabalho. Os dados fundamentais para a elaboração deste projeto são classificados de forma quantitativa e qualitativa.

\section{III.6.3 COLETA DE DADOS}

O levantamento de dados foi realizado no período de março de 2017. Para a realização da coleta de dados, se fez necessário extrair algumas informações da empresa, especificamente no posto de trabalho estudado. Os dados referentes ao processo são: Tempo Efetivo, Produção por turno, Produção por hora, Produção por minuto, Ciclo de trabalho, Ciclo de trabalho real, Taxa de ocupação e Taxa de Repouso serviram para a elaboração de uma tabela de organização do trabalho.

\section{III.6.4 RECURSOS E EQUIPAMENTOS UTILIZADOS}

Para a realização deste trabalho, foi necessário a utilização de um computador (Sistema Operacional Windows 7 e Office 2013), um celular, prancheta, uma calculadora, um termômetro, um medidor de luminosidade, um medidor de ruído, um medidor de umidade relativa do ar e um medidor de velocidade do ar.

\section{RESULTADOS E DISCUSSÕES}

\section{IV.1 DESCRIÇÃO DA EMPRESA}

A empresa estudada está no Pólo Industrial de Manaus desde 1975. A produção é voltada para bicicletas com alta tecnologia, além da linha fitness, formada por aparelhos de ginástica para prática indoor, mobylettes e patinetes. Posicionada como uma empresa contemporânea, a empresa é reconhecida como marca top of mind em bicicletas, tendo uma linha composta por aproximadamente 35 modelos, divididos nos segmentos: infantil, mountain bike, passeio e transporte.

A empresa propicia a Infra-estrutura necessária para alcançar conformidades dos requisitos dos produtos, incluindo área de trabalho, equipamentos e serviços de apoio. Assegura que o ambiente de trabalho esteja em condições necessárias para alcançar as conformidades com os requisitos dos produtos, de forma a garantir que as atividades definidas nas Instruções de trabalho possam ser efetivamente realizadas.

A empresa emprega 900 funcionários e tem em Manaus a maior fábrica de bicicletas do mundo fora do sudeste da Ásia, com a produção de mais de 700 mil unidades por ano.

\section{IV.2 ESTRUTURA FÍSICA}

$\begin{array}{ll}\checkmark & \text { Galpão Industrial; } \\ \checkmark & \text { Ventilação Natural e ventiladores; } \\ \checkmark & \text { Construído de paredes de alvenaria; } \\ \checkmark & \text { Ar Refrigerado (Apenas em áreas Administrativas) } \\ \checkmark & \text { Não há Isolamento Térmico; } \\ \checkmark & \text { Vigas de Aço; } \\ \checkmark & \text { Coberto com telhas de Alumínio. }\end{array}$

\section{IV.3 DADOS AMBIENTAIS}

Tabela 1: Dados ambientais da empresa estudada.

\begin{tabular}{|c|c|c|c|}
\hline Condições Ambientais & Referência & $\begin{array}{c}\text { Valor } \\
\text { Medido }\end{array}$ & Comentário \\
\hline Iluminamento & NR 17 - 17.5.2 - NBR 8995-1:2013 A partir de 300 Lux & 463 Lux & Adequado \\
\hline Ruído & NR17 - 17.5.2 Até $85 \mathrm{~dB}(\mathrm{~A})$ & $89,1 \mathrm{~dB}(\mathrm{~A})$ & Inadequado \\
\hline Temperatura & NR 15 - Anexo 3 Trabalho moderado Até $26,7^{\circ} \mathrm{C}$ & $30,7^{\circ} \mathrm{C}$ & Inadequado \\
\hline Umidade Relativa do Ar & NR17 - 17.5.2 Acima de 40\% & $59,8 \%$ & Adequado \\
\hline Velocidade do Ar & NR17 - 17.5.2 Até $0,75 \mathrm{~m} / \mathrm{s}$ & $3,5 \mathrm{~m} / \mathrm{s}$ & Inadequado \\
\hline
\end{tabular}

Fonte: Autores, (2017).

\section{IV.4 DESCRIÇÃO DETALHADA DAS ATIVIDADES DO POSTO DE TRABALHO}

Nome do posto: Soldar pernas + reforço do garfo

$\checkmark$ Realiza o trabalho em duas máquinas de solda simultaneamente.

$\checkmark$ Retira um reforço da caixa de montagem e posiciona no gabarito de solda.

$\checkmark$ Retira o conjunto que contém as pernas do garfo e as posiciona no gabarito de solda, de forma a unir as partes. Fecha a proteção da máquina de solda. $\checkmark$ Aguarda o processo de solda que ocorre automaticamente após o fechamento da proteção.

$\checkmark$ Realiza o mesmo procedimento com a segunda máquina.

$\checkmark \quad$ Um trabalhador é responsável pela execução das tarefas do posto de trabalho, revezando as tarefas ao longo da jornada de trabalho com outra máquina com a mesma função, dimensões e características.

$\checkmark \quad$ Na postura em pé retira um reforço que está posicionado em caixa de montagem a esquerda do corpo.

$\checkmark$ Posiciona o reforço no gabarito de solda, se deslocando cerca de 1 metro para alcançar o gabarito. 
$\checkmark$ Se deslocar novamente a caixa de montagem e retira "as pernas do garfo".

$\checkmark$ Posiciona "as pernas do garfo" no gabarito de solda de forma a uni-las ou aproxima-las fisicamente.

$\checkmark$ Aciona botoeira posicionada a direita da máquina e acoplada a esta. O comando indicará o fechamento da proteção da máquina de solda.

$\checkmark$ Enquanto a primeira máquina realiza a solda, o trabalhador se desloca até a caixa de montagem e retira o reforço que será utilizado na segunda máquina de solda.

$\checkmark$ Posiciona o reforço no gabarito de solda da segunda máquina.

$\checkmark$ Se deslocar novamente até a caixa de montagem e retira "as pernas do garfo" e transporta até a segunda máquina.

$\checkmark$ Posiciona "as pernas do garfo" no gabarito de solda e trava a alavanca que prende as peças.

$\checkmark$ Fecha manualmente a porta que protege o trabalhador da solda.

\section{IV.5 MÉTODO DE TRABALHO:}

O turno de trabalho é das 07:12 h às 17:00 h, pausa para refeição de 1 h e pausa de 5 a 10 minutos de ginástica laboral realizada no próprio setor. Ciclo de trabalho é de 25,0 segundos para realizar o processo de solda nas duas máquinas. $\mathrm{O}$ trabalhador permanece neste posto de trabalho durante toda a jornada sem revezamento estabelecido.

Observa-se ritmo acelerado de trabalho durante a execução do ciclo de trabalho, entretanto, as pausas podem ser voluntárias devido a descontinuidade da produção em alguns momentos. Existe tempo para alternância de posturas e revezamentos quando necessário.

O trabalhador não possui autonomia para a realização de pausas ao longo da jornada de trabalho. A meta estipulada para este posto de trabalho é de 800 peças soldadas por turno. Em média são soldadas 2 peças por minuto, o que torna a meta viável para ser realizada por apenas um funcionário, e abre o precedente de que são possíveis pausas voluntárias e revezamento da postura ao longo da jornada de trabalho.

\section{IV.6 ORGANIZAÇÃO DO TRABALHO}

$\checkmark$ Jornada de Trabalho: 07:12 às 17:00 horas

$\checkmark$ Ginástica laboral: 09:30 às 09:40 horas

$\checkmark$ Tempo para refeição: 12:00 às 13:00 horas

A Tabela 2 mostra os dados coletados no processo de solda da perna do garfo.

Tabela 2: Dados do processo.

\begin{tabular}{|c|c|c|}
\hline Item & Valor & Classe \\
\hline Tempo Efetivo & $08: 38$ & horas \\
\hline Produção por turno & 800 & unidades/turno \\
\hline Produção por hora & 92,7 & unidades/hora \\
\hline Produção por minuto & 1,5 & unidades/minuto \\
\hline Ciclo de trabalho & 40 & segundos/peças \\
\hline Ciclo de trabalho real & 25 & segundos/peças \\
\hline Taxa de ocupação & $62,5 \%$ & $\%$ \\
\hline Taxa de Repouso & 37,5 & $\%$ \\
\hline
\end{tabular}

Fonte: Autores, (2017).

\section{IV.7 MENSURAÇÃO DO ESPAÇO FÍSICO DO POSTO E PESOS MANIPULADOS}

Trata-se de um posto de trabalho em um setor composto por um trabalhador realizando a mesma função e tarefas. O trabalhador realiza a atividade na postura em pé com deslocamentos de até 2 metros na frente da máquina. As máquinas estão dispostas uma na frente da outra com espaço de 2 metros entre elas. Nesse espaço o trabalhador se desloca e necessita retirar as peças de montagem. A figura 3 mostra o local de trabalho.

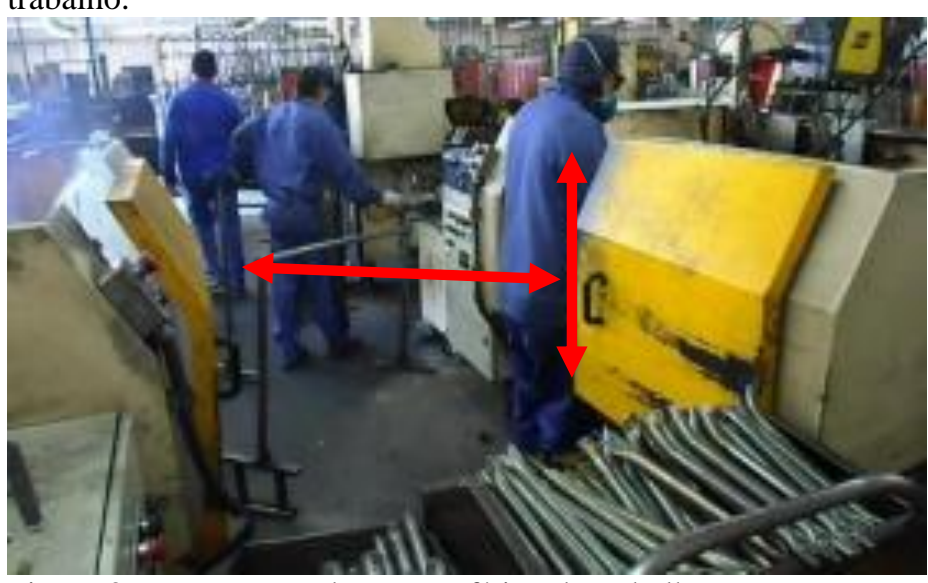

Figura 3: Mensuração do espaço físico de trabalho.

Fonte: Autores, (2017).

O colaborador desloca-se cerca de $2 \mathrm{~m}$ de uma. A Altura da Cintura do colaborador cerca 1,2 m.

\section{IV.7.1 REGISTRO FOTOGRÁFICO}

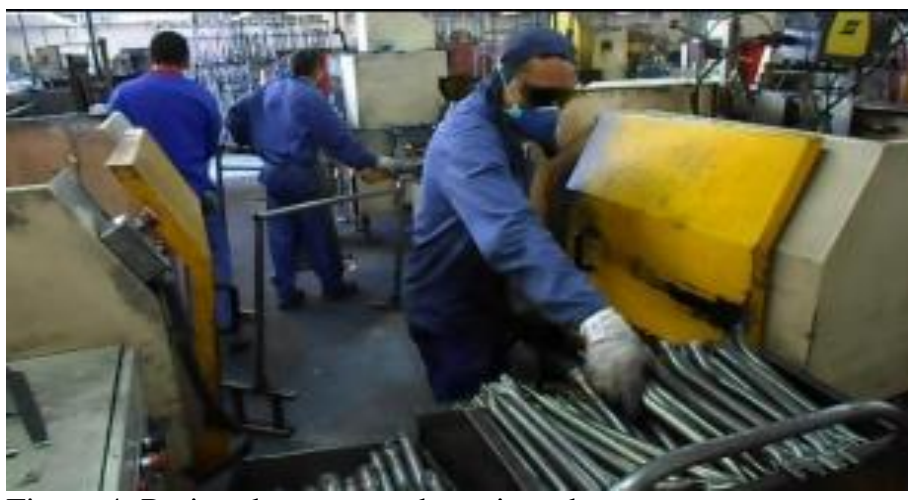

Figura 4: Retirando as peças das caixas de montagem.

Fonte: Autores, (2017).

Deslocamentos constantes com mudança de direção e manuseio de carga baixa ao longo de toda a jornada de trabalho. Movimento biomecânico realizado: Extensão de braço.

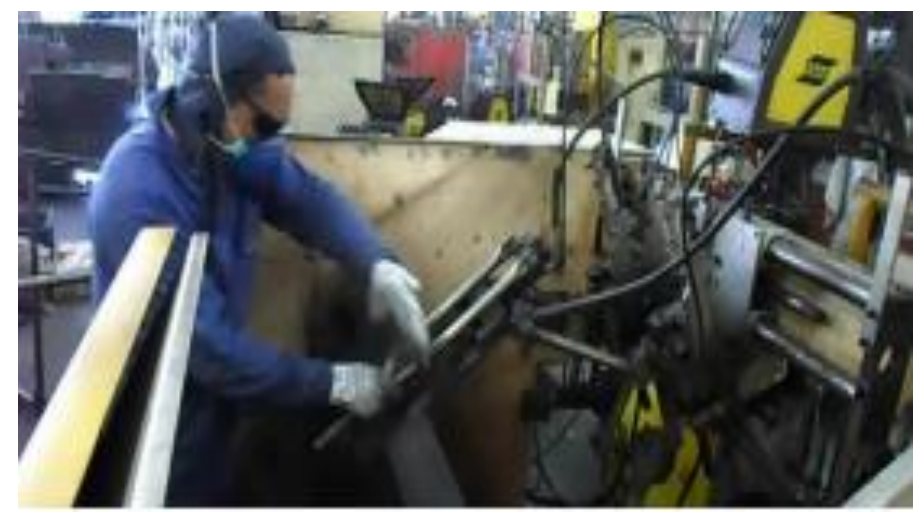

Figura 5: Encaixando as peças no gabarito.

Fonte: Autores, (2017). 


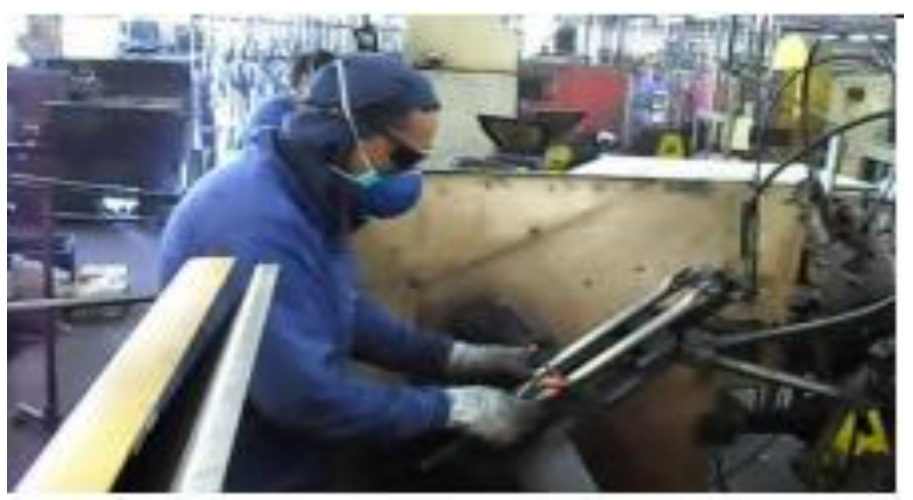

Figura 6: Fechando à alavanca que trava as peças no gabarito de solda.

Fonte: Autores, (2017).

Observa-se que o Movimento biomecânico realizado é uma discreta flexão de cervical.

Movimento biomecânico realizado: Abdução de ombro esquerdo para fechar a alavanca no gabarito.

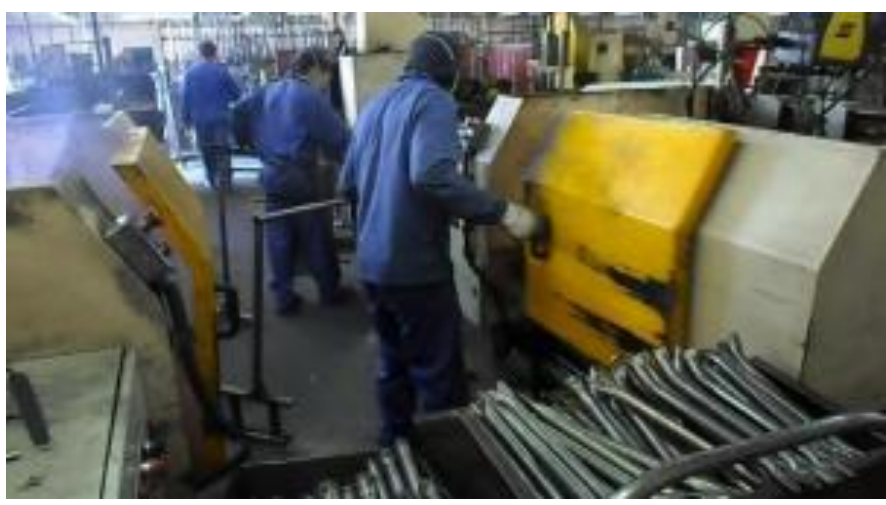

Figura 7: Fechando manualmente a porta.

Fonte: Autores, (2017).

Movimento biomecânico realizado: Força com flexão de cotovelos para puxar a porta de uma das máquinas.

\section{IV.7.2 RESULTADO DA ANÁLISE ERGONÔMICA}

Tabela 3: Método Sue Rogers

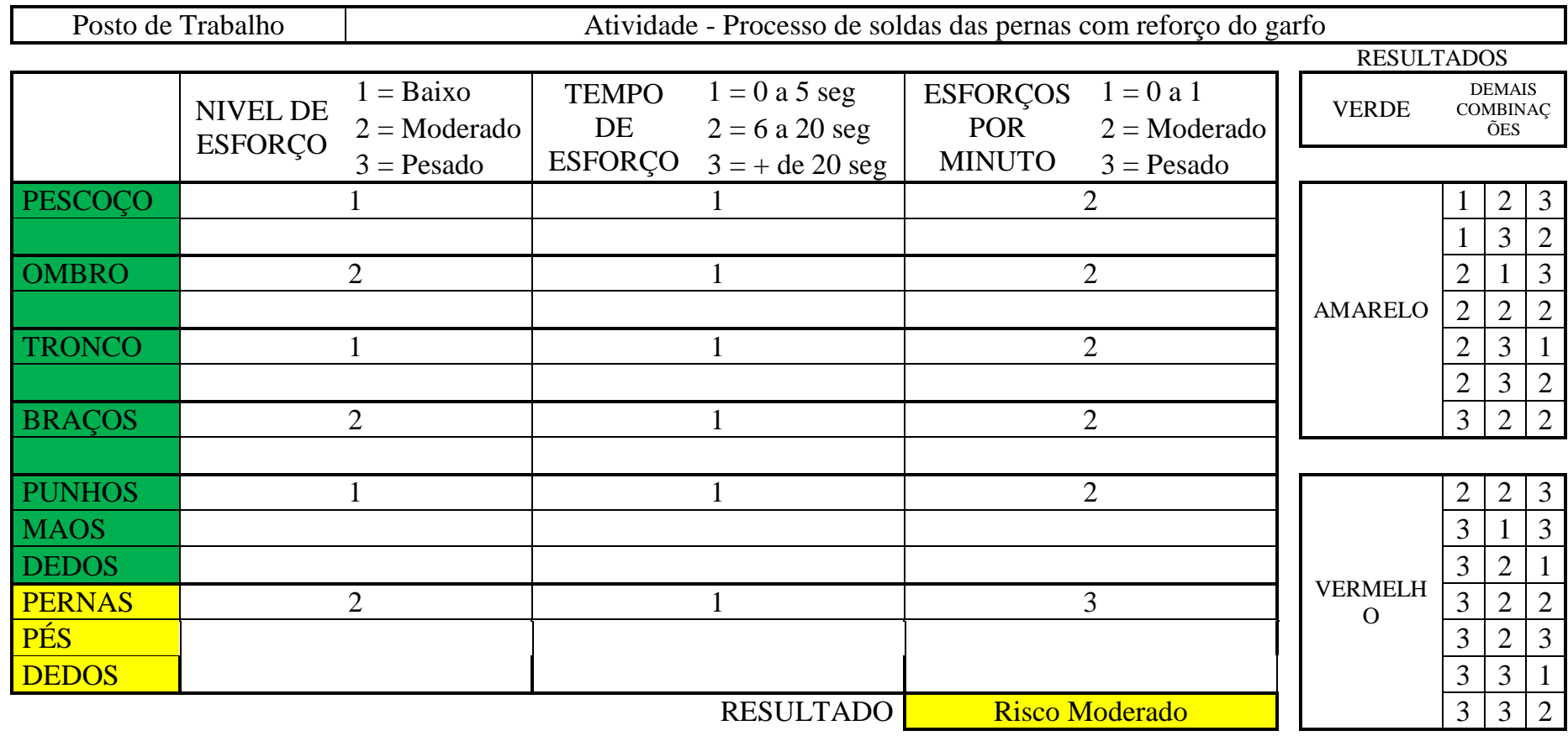

Fonte: Autores, (2017).

Na tabela 4 a ferramenta de análise demonstra que os riscos envolvidos na atividade de trabalho são:

Tabela 4: Riscos ergonômicos.

\begin{tabular}{|c|l|l|}
\hline FERRAMENTA & RESULTADO & REGIÃO CORPÓREA \\
\hline SUE RODGERS & Risco Baixo & Pescoço \\
(Análise de esforço para & Risco Baixo & Ombro \\
segmentos corpóreos) & Risco Baixo & Tronco \\
Atividade: Processo de & Risco Baixo & Braços \\
solda das pernas com o & Risco Baixo & Punhos, Mãos e dedos \\
reforço do garfo. & Risco Moderado & Pernas, Pés e dedos \\
& & \\
\hline
\end{tabular}

Fonte: Autores, (2017).

Conforme resultado da ferramenta ergonômica aplicada e análise realizada chega-se ao seguinte laudo técnico do posto de trabalho:
Risco moderado para pernas, devido aos constantes giros do corpo para alimentar com peças as duas máquinas de solda, sem possibilidade de revezamento e durante toda a jornada de trabalho. 


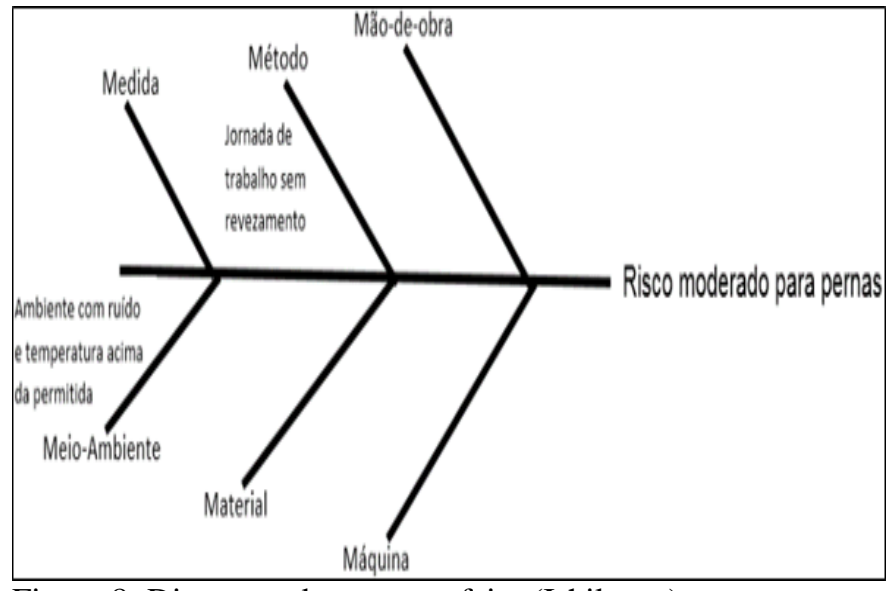

Figura 8: Diagrama de causa e efeito (Ishikawa).

Fonte: Autores, (2017).

\section{CONCLUSÃO}

O resultado da análise ergonômica no posto de trabalho solda + reforço do garfo, através da ferramenta Suzanne Rodgers, mostra que os riscos envolvidos nas atividades são classificados como baixo, com exceção das pernas que tem o risco moderado conforme a tabela 4. Neste estudo foi encontrado algumas situações inadequadas no posto de trabalho como: o ruído que ultrapassa o limite máximo de $85 \mathrm{~dB}$ conforme a NR17.5.2. O nível de ruído foi de $89,1 \mathrm{~dB}$, o que torna o ambiente inadequado para trabalhar, porém o colaborador utiliza o EPI (protetor auricular). A temperatura do posto foi medida em $30,7{ }^{\circ} \mathrm{C}$, tornando o local de trabalho insalubre. A velocidade do ar está acima do recomendado pela norma NR17 - 17.5.2. Conclui-se que o posto de trabalho necessita ser melhorado com o objetivo oferecer boas condições de trabalho para o colaborador, para que o desempenho do processo seja satisfatório, diminuindo os riscos ergonômicos, doenças osteomusculares e desconforto físico e mental.

\section{V.1 SUGESTÕES DE MELHORIA}

Segue abaixo algumas sugestões de melhorias para o posto de trabalho conforme a tabela 5 .

Tabela 5: Sugestões de melhoria.

\begin{tabular}{|l|l|l|}
\hline Sugestão & Objetivo & Adequação a Norma NR17 \\
\hline $\begin{array}{l}\text { Verificar a possibilidade de realizar o } \\
\text { trabalho com 2 trabalhadores. }\end{array}$ & $\begin{array}{l}\text { Não gera excesso de } \\
\text { fadiga ao operador. }\end{array}$ & $\begin{array}{l}\text { O contingente de operadores deve ser dimensionado às } \\
\text { demandas da produção no sentido de não gerar sobrecarga } \\
\text { habitual ao trabalhador (NR 17, item 5.2). }\end{array}$ \\
\hline $\begin{array}{l}\text { Disponibilizar o fechamento } \\
\text { automatizado e Inter travado com a } \\
\text { solda nas duas máquinas }\end{array}$ & $\begin{array}{l}\text { Evitar possível uso/ou } \\
\text { exigência acentuada } \\
\text { de força }\end{array}$ & $\begin{array}{l}\text { NR17.2.2-Item a) escolhê-los de modo a favorecer os } \\
\text { movimentos e açóes próprias da função, sem exigência } \\
\text { acentuada de força, pressão, preensão, flexão, extensão ou } \\
\text { torção dos segmentos corporais; }\end{array}$ \\
\hline $\begin{array}{l}\text { Incluir na instrução de trabalho o } \\
\text { revezamento para a postura sentada a } \\
\text { cada duas horas. }\end{array}$ & $\begin{array}{l}\text { Evitar o cansaço em } \\
\text { uma única postura }\end{array}$ & $\begin{array}{l}\text { NR 17.3.5. Para as atividades em que os trabalhos devam } \\
\text { ser realizados de pé, devem ser colocados assentos para } \\
\text { descanso em locais em que possam ser utilizados por todos } \\
\text { os trabalhadores durante as pausas. }\end{array}$ \\
\hline $\begin{array}{l}\text { Adotar sistema de revezamento e } \\
\text { enriquecimento da tarefa: propiciar } \\
\text { novas atividades e de maior } \\
\text { complexidade que se insiram no ciclo } \\
\text { de trabalho do colaborador. Como por } \\
\text { exemplo: realizar checklist diário da } \\
\text { organização e limpeza dos postos de } \\
\text { trabalho. }\end{array}$ & $\begin{array}{l}\text { Garantir } \\
\text { flexibilidade } \\
\text { atividades para os } \\
\text { coloboradores }\end{array}$ & $\begin{array}{l}\text { NR } \\
\text { checkouts com características diferentes; }\end{array}$ \\
\hline $\begin{array}{l}\text { Desenvolver e instituir pausas regulares } \\
\text { no trabalho, a fim de propiciar } \\
\text { mecanismos de compensação muscular, } \\
\text { tanto para membros superiores quanto } \\
\text { para membros inferiores. }\end{array}$ & $\begin{array}{l}\text { Evitar fadigas } \\
\text { musculares }\end{array}$ & NR 17.4.1 item d) d) pausas durante a jornada de trabalho. \\
\hline
\end{tabular}

Fonte: Autores, (2017).

\section{REFERÊNCIAS}

[1] Capelari, J; Scheibig, K; Dieter, E; LER/DORT e os Riscos a Saúde do Trabalhador: Uma Revisão Bibliográfica 2008. Revista FisioBrasil, Ano 12 - Edição no 96 - Agosto de 2009 ISSN 1676-1324.

[2] Vieira, Sebastião. Medicina Básica do Trabalho. São Paulo: Thomsom Pioneira, 1996.

[3] Dejours, Christophe, et al. Psicodinâmica do trabalho: contribuições da escola dejouriana à análise da relação prazer, sofrimento e trabalho. Atlas, 1994.

[4] Wisner, A. Por dentro do trabalho. São Paulo: Oboré, 1987.
[5] ASSOCIAÇÃO BRASILEIRA DE ERGONOMIA. O que é ergonomia. [s.d.]. Disponível em: Acesso em: 28 fev. 2017.

[6] INTERNATIONAL ERGONOMICS ASSOCIATION (IEA). What is ergonomics? IEA, 2015. Disponível em: Acesso em: 03 mar 2017.

[7] Attwood, D. A.; Deeb, J. M.; Danz-Reece, M. E. Ergonomic Solutions for the Process Industries. Elsevier Inc. 2004. 
[8] Wisner, Alain. A metodologia na ergonomia: ontem e hoje. A inteligência no trabalho: textos selecionados de ergonomia. São Paulo: Fundacentro, p. 87-107, 1994.

[9] Iida, I. Ergonomia: projeto e produto. São Paulo, E. Blücher, 1993.

[10] Moraes, A.; Mont'alvão, C. Ergonomia: conceitos e aplicações. Rio de Janeiro: A. de Moraes, 2005.

[11] Pheasant, S. Bodyspace. Anthropometry, Ergonomics and the Design of Work. London: Taylor \& Francis, 1997.

[12] Márias, F. Leonardo da Vinci: grandes mestres da pintura clássica. Lisboa: Editorial, Ed. Estampa, 1997.

[13] Martins, Petrônio G e Laugeni, Fernando P. Administração da Produção. 2 ed. São Paulo, 2006.

[14] Taveira Filho, A. Ergonomia participativa: uma abordagem efetiva em macroergonomia. Produção. v.3, n.2, p.87-95, nov./1993.

[15] Hochmuth, G. Biomecânica dos movimentos esportivos. Ed Ruan S.A., Madrid, 1973.

[16] Willimczik, K. Biomechanik der Sportarten. Reinbek bei Hamburg: Rowohlt Taschenbuch Verlag GmbH, (1989)

[17] Iida, I. Ergonomia - produção e projeto. Editora Edgard Blücher Ltda, São Paulo, SP, 1990.

[18] Rodgers, Método Suzanne. Software de Ergonomia/Fisioterapia do trabalho para avaliação dos postos de trabalho e melhoria da saúde ocupacional. 2008.

[19] Gil, Antônio Carlos. Como elaborar projetos de pesquisa. São Paulo, v. 5, n. 61, p. 16-17, 2002.

[20] Lakatos, E.M, Marconi, M.A. Técnicas de Pesquisa. São Paulo: Atlas, 1999. 